\title{
Design and Analysis of Second and Third Order PLL at 450MHz
}

\author{
B. K. Mishra ${ }^{1}$, Sandhya Save $^{2}$, Swapna Patil ${ }^{1}$ \\ ${ }^{1}$ Department of Electronics and Telecommunication Engineering,TCET, Mumbai \\ University, India \\ drbk.mishra@thakureducation.org \\ tambakuswapna@rediffmail.com \\ ${ }^{2}$ Department of Electronics Engineering, TCET,Mumbai University, India \\ save_sandhya@rediffmail.com
}

\begin{abstract}
Designing of an analog circuit satisfying the design constraints for desired application is a challenging job. Phase Lock Loop (PLL) is an important analog circuit used in various communication applications such as frequency synthesizer, radio, computer, clock generation, clock recovery, global positioning system, etc. Since all these applications are operating at different frequency, satisfying design constraints for PLL with respect to type of PLL operating frequency, Bandwidth, Settling time and other parameters is an critical and time consuming issue. In this paper, selection and design for Second order and third order PLL suggested using MATLAB, Simulink as a simulation tool. The simulated results for the design PLL at $450 \mathrm{MHz}$ indicates good accuracy when the behavior model is compared with the mathematical model. Finally the performance of PLL is tested and calculated for parameters like lock time, lock range, Bandwidth.
\end{abstract}

\section{KEYWORDS}

PLL, Charge Pump PLL, Baseband PLL, VCO, Simulink, CAD, EDA tool.

\section{INTRODUTION}

Phase locked loop is an excellent research topic as it covers many disciplines of electrical engineering such as Communication Theory, Control Theory, Signal Analysis, Noise Characterization, Design with transistors and op-Amps, Digital Circuit design and non-linear circuit analysis. The first PLL ICs came in existence around 1965 was built using purely analog devices. Recent advances in integrated circuit design techniques have led to an increased use of the PLL as it has become more economical and reliable. Now a whole PLL circuit can be integrated as a part of a larger circuit on a single Chip i.e SoC [1] [13]. MATLAB simulink [15] is effective tool to get prior idea about PLL parameters to fulfill requirements before actual chip design. 
Phase-locked loops [17] are known to have plenty of applications, from low-frequency ones, e.g., motor controller [18] and synchronous power converters [19], to RF applications, e.g., frequency synthesizers [2][20]. For low-speed applications, phase-locked loop (PLL) systems can be implemented in DSP [19], [21]. On the other hand, for high-speed applications, PLL systems are realized in analog way [18], [20]and in digital way [3]. The accuracy of the required frequencies is very important in these designs as the performance is based on this parameter [1] [13] [4].

As the name suggests, the phase locked loop operates by trying to lock to the phase of a very accurate input signal through the use of its negative feedback path. A basic form of a PLL consists of three fundamental functional blocks namely Phase Detector (PD), Loop Filter (LF), Voltage Controlled Oscillator (VCO).The block diagram of PLL is shown in the figure 1.The different types of PLL can broadly categories as Analog PLL, Digital PLL and Hybrid PLL.

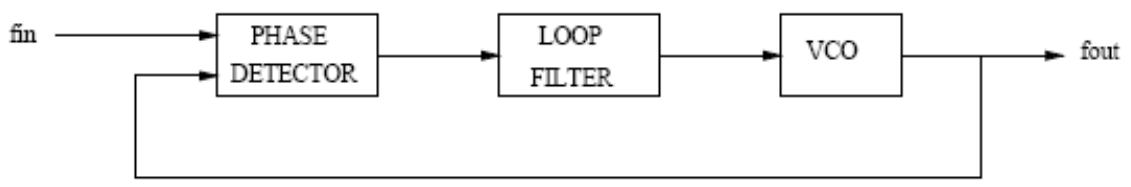

Figure 1. The block diagram of PLL

The presence of two nonlinear devices as phase-detector and VCO, in closed loop makes PLL, a nonlinear device. Therefore in this work, the performance of PLL designed for $450 \mathrm{MHz}$ frequency is tested against VCO sensitivity, free running frequency, amplitude and phase of VCO, Loop filter transfer function.

The remainder of the paper is organized as follows. In Section 2, the basic of Linearized model of PLL and structure of third order PLL is explained. The equation for lock time $\left(T_{L}\right)$, Bandwidth $(B W)$ and lock range $\left(\Delta w_{L}\right)$ is listed. In section 3, the frame for PLL design using Matlab/Simulink is explained. In section 4, the obtained results were compared with theoretical calculation.

\section{LINEARIZED PHASE DOMAIN MODEL FOR PLL}

The generalized loop response for the higher ordered PLL can be written as equation 1[1], [2], [14]

$\frac{\theta_{0}}{\theta_{i}}=\frac{K_{p} K_{v} F(s)}{s+K_{p} K_{v} F(s)} \ldots \ldots \ldots \ldots \ldots \ldots \ldots \ldots \ldots \ldots$

Where,

$\theta_{0}=$ the output phase in radians

$\theta_{i}=$ the input phase in radians

$K_{p}=$ the phase detector gain in volts per radian 
$K_{v}=$ the $\mathrm{VCO}$ gain in radians per volt-second

$F(s)=$ the loop filter transfer function (dimensionless)

The loop characteristics can be controlled by changing different types of loop filters then the order of PLL is ${ }_{n+1}$ where $n$ order of the loop filter.

The simplest filter is a one-pole RC circuit. The loop transfer function in this case is given an equation 2.

$F(s)=\frac{1}{1+s R C}$

The loop response for $2^{\text {nd }}$ order PLL can be found out using equation (2), (3).

$$
\frac{\theta_{0}}{\theta_{i}}=\frac{\frac{K_{p} K_{v}}{R C}}{s^{2}+\frac{s}{R C}+\frac{K_{p} K_{v}}{R C}}
$$

Comparing the equation (3) with standard transfer function equation of second order filter we get,

$$
\begin{aligned}
& \xi=1 / \sqrt[2]{K_{p} K_{v} R C} \\
& \omega_{n}=\sqrt{K_{p} K_{v} / R C} \cdots
\end{aligned}
$$

Where,

$R C=$ Time constant in sec.

$\xi=$ damping ratio

$\omega_{n}=$ natural frequency

For sinusoidal phase detector $K_{P}$ is $1 / 2$ of peak to peak voltage of PD output [4].

Using equation (3), (4), (5) we get,

Lock time, $T_{L}=2 \Pi / \omega_{n}$

Lock range, $\Delta w_{L}=\Pi \xi \omega_{n}$

Bandwidth, $B W=\omega_{n}\left[1-2 \xi^{2}+\left(2-4 \xi^{2}+4 \xi^{4}\right)^{1 / 2}\right]^{1 / 2}$

Using these mathematical model formulae, the corresponding values for lock time, Lock range, Bandwidth is calculated for different types of PLL, Baseband PLL, Charged Pump PLL [2]. While designing charged pump PLL the pump current $I_{p}$ and selection of $\mathrm{C}($ mostly in $\mathrm{nF})$ are the 
important design factor to be considered. Typically for most of the designs value of Ip is $100 \mu A$ to $1 m A$ [2] [7] [4].

$\omega_{n}=\sqrt{\frac{I_{p} K v c o}{2 \Pi C_{p}}}$

$\xi=R_{p} \sqrt{\frac{I_{p} c_{p} K v c o}{2 \Pi}}$

As expected, if $\mathrm{Rp}=0$, then $\zeta=0$. With complex poles, the decay time constant is given by equation (11)

$\frac{1}{\xi \omega_{n}}=\frac{4 \Pi}{R_{p} I_{p} K_{v c o}}$

As seen from the closed loop transfer function of second order PLL. [2] if we decrease the $I_{p} * K_{v c o}$, the gain crossover frequency decreases (or shifts toward the origin), degrading the phase margin. But this compensated type PLL suffers from a drawback. Since the charge pump drives the series combination of $R_{P}$ and $C_{P}$, each time a current is injected into the loop filter, the control voltage experiences a large jump. Even in the locked condition, mismatches between I $I_{U P}$ and $I_{D O W N}$ and the charge pump injection and clock feed through of S1 and S2 introduce voltage jump in $V_{C O N T}$ as shown in figure 3.

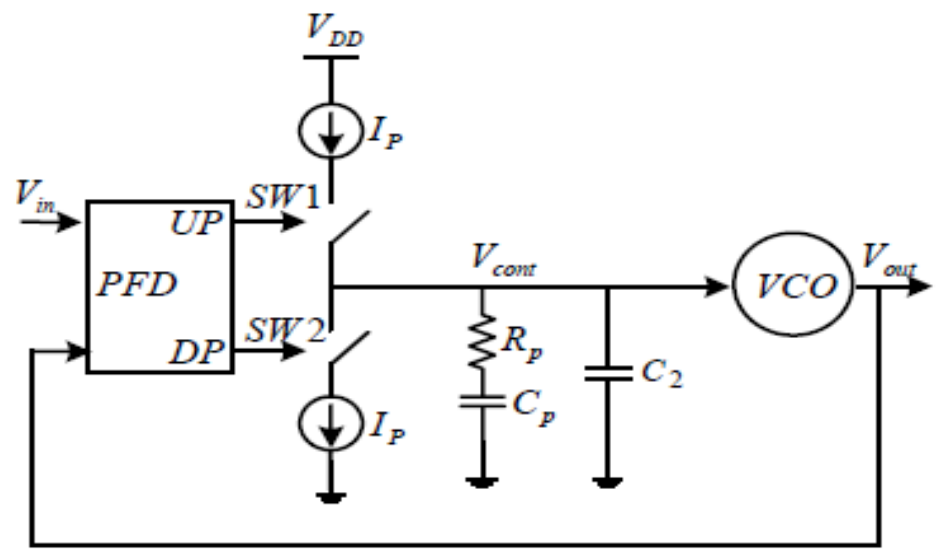

Figure.2. Structure of third order charge pump PLL 


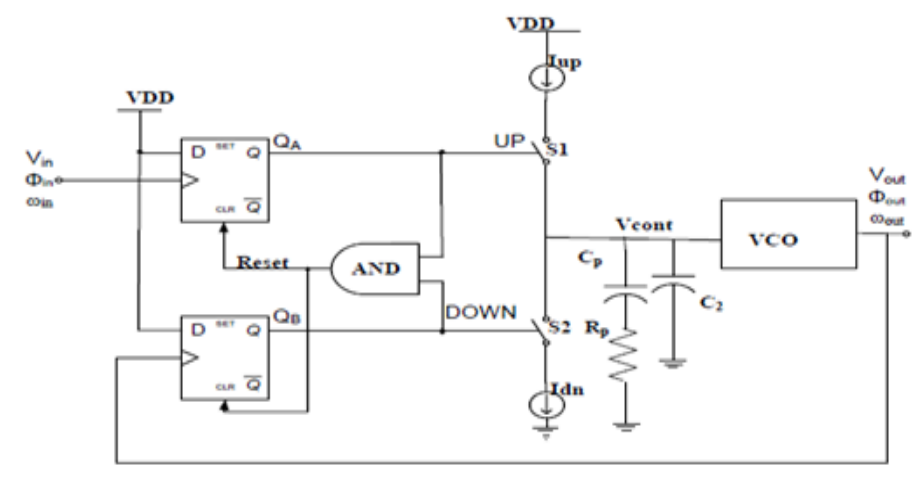

Figure. 3.Addition of $\mathrm{C} 2$ to improve stability

Design and analysis of third order PLL is important as higher order design are concerns with system stability designed for wide applications. Transfer function for second order filter for charge pump PLL is given by equation (12). The structure of third order charge pump PLL and System model of charge pump PLL block diagram shown in figure 2,figure 4 respectively.

Transfer function of loop filter is given by equation (12)

$\left\{R p+1 / C_{P} S\right\} / / 1 / C_{2} S$

The open loop and closed loop transfer function is given by equations (12), (13).

$$
\begin{gathered}
G_{0}(s)=\frac{\frac{I_{p} K_{v c o}}{2 \pi}\left(s R C_{1}+1\right)}{S^{3} R C_{1} C_{2}+S^{2}\left(C_{1}+c_{2}\right)} \\
G_{c}(s)=\frac{\frac{s I_{p} K_{v c o} R}{2 \Pi}+\frac{I_{p} K_{v c o}}{2 \Pi C_{1}}}{s^{3} m R C_{1}+\frac{s I_{p} K_{v c o} R}{2 \Pi}+\frac{I_{p} K_{v c o}}{2 \Pi C_{1}}}
\end{gathered}
$$

Where, $I_{p}$ is the current of charge pump,

$K_{v c o}$ is the VCO gain constant

$\mathrm{m}=\frac{c_{2}}{c_{1}}$ is the capacitance ratio.

Usually, $\mathrm{C} 2$ is much smaller than $\mathrm{C} 1(\mathrm{~m} \ll 1)$. Comparing equation (13) with equation (14) will get $\xi, \omega_{n}$ and $\mathrm{m}$. 


$$
G_{c}(s)=\frac{2 \xi \omega_{n} s+\omega^{2}}{m \frac{2 \xi}{\omega_{n}} s^{3}+(m+1) s^{2}+\omega_{n}^{2}}
$$

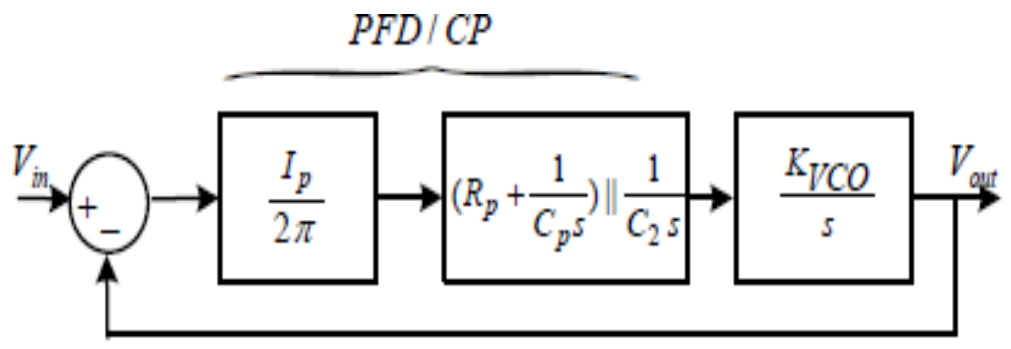

Figure 4.System model of charge pump PLL block diagram

\section{FRAME WORK FOR PLL DESIGN}

The set up arrangement done for PLL( Charge Pump PLL )is parameter measurement is shown in the figure 5 .

\subsection{Setup for PLL Simulation in Simulink}

The input provided in set up is the order coefficient of Loop filter. For e.g., using the transfer function of Loop filter incorporated in automated program written in Matlab which guides to find the input to find the proper range of input applied to the set up assembly to get desired output. Similarly for other input parameters Like, VCO gain in Hz/volts and quiescent frequency were found out.

For analysis of third order PLL setup used is almost same as second order PLL, Input for assemble are Transfer Function of loop filter, Kvco, quiescent frequency of VCO.

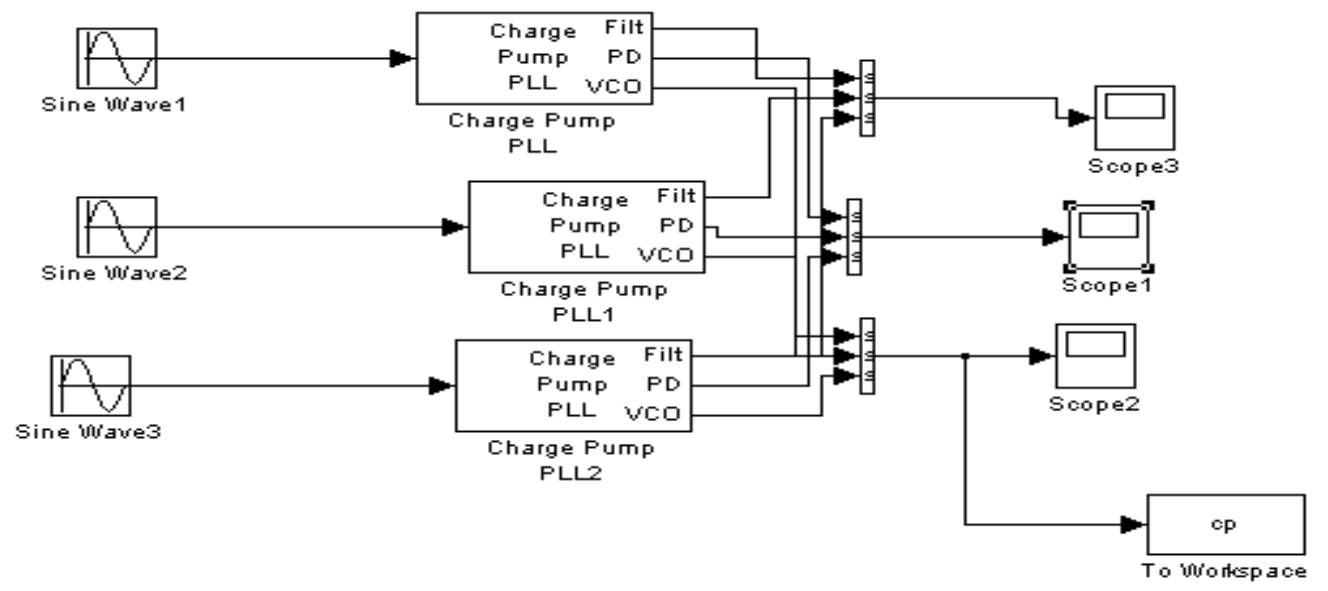

Figure 5. Setup for measurement of PLL parameters in Simulink 


\subsection{Measurement of PLL parameters}

The simulation is done in Simulink/Matlab 2009b on Intel processor core 2 Duo processor@ $2.93 \mathrm{GHz}$ with $1.96 \mathrm{GBRAM}$.The simulated results for filter output ,phase detector output and VCO outputs can seen in real time using scope in Simulink. The obtained VCO output filter output, Phase detector output for Charge pump PLL is shown in figure 7, figure 8 and figure 9 respectively. Similarly filter output (control signal),PD output and reference signal \& VCO output shown in figure 10,11,12 respectively. These obtained data at least 5000 samples per result were stored in workspace. The peak value i. e $A 1$ and next peak value $A 2$ are found out from these samples using program written in Matlab [9], [10]. Using these retrieved values $\xi$ and $\omega_{n}$ was found out using the formulae figure 6 [4].The automated program files guides to find calculated and observed value for given RC time constant.

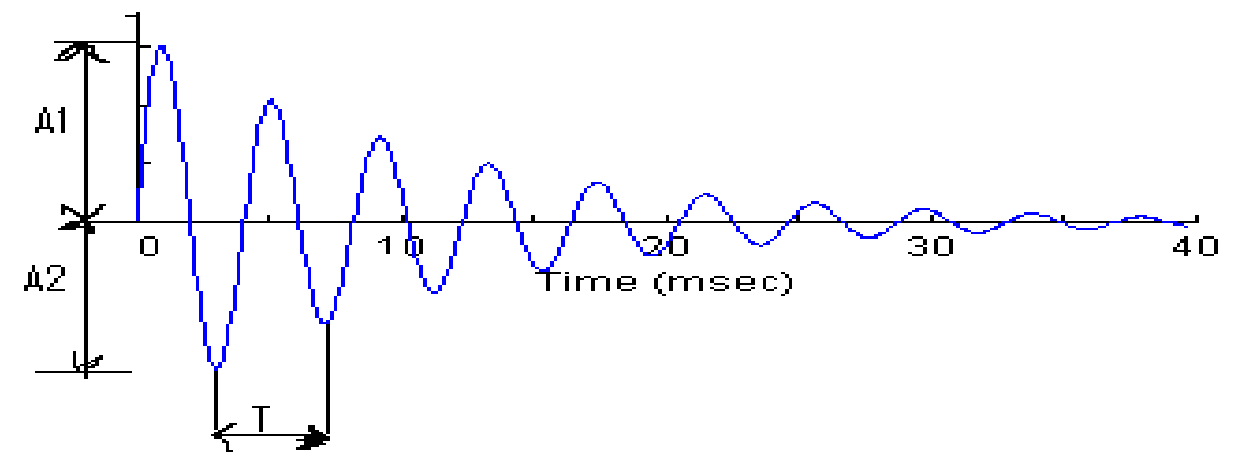

Figure 6. Measurement of PLL

$$
\begin{aligned}
& \xi=\frac{\ln (A 1 / A 2)}{\sqrt{\Pi^{2}}+\left[\ln (A 1 / A 2)^{2}\right]} \\
& \omega_{n}=\frac{2 \Pi}{T \sqrt{1-\xi^{2}}}
\end{aligned}
$$

Where,

${ }_{A 1}=$ First maximum peak amplitude

$A 2=$ First minimum peak amplitude 
International Journal of VLSI design \& Communication Systems (VLSICS) Vol.2, No.1, March 2011

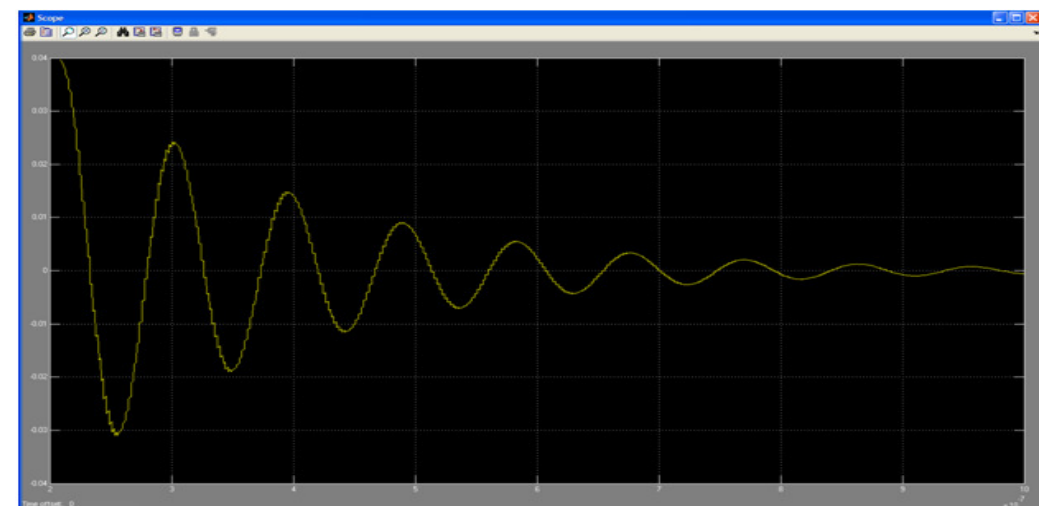

Figure 7. Charge pump PLL filter output

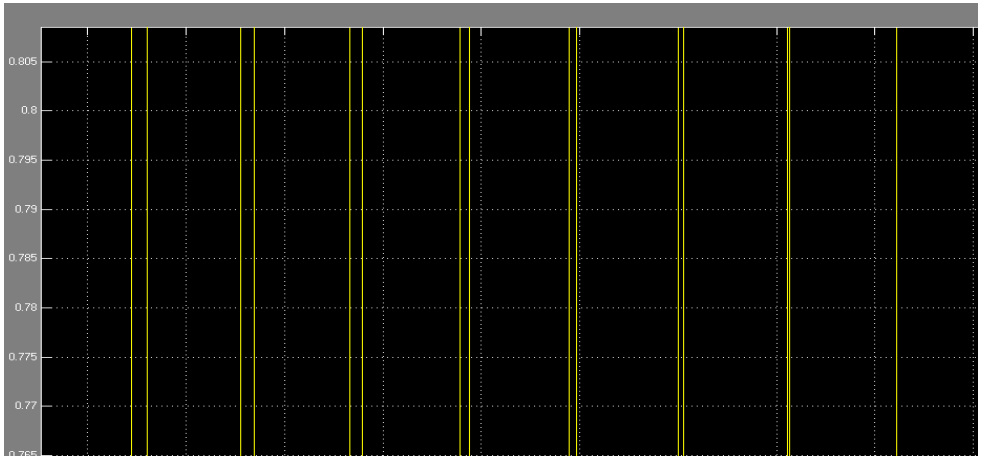

Figure 8. Charge pump PLL Phase detector output

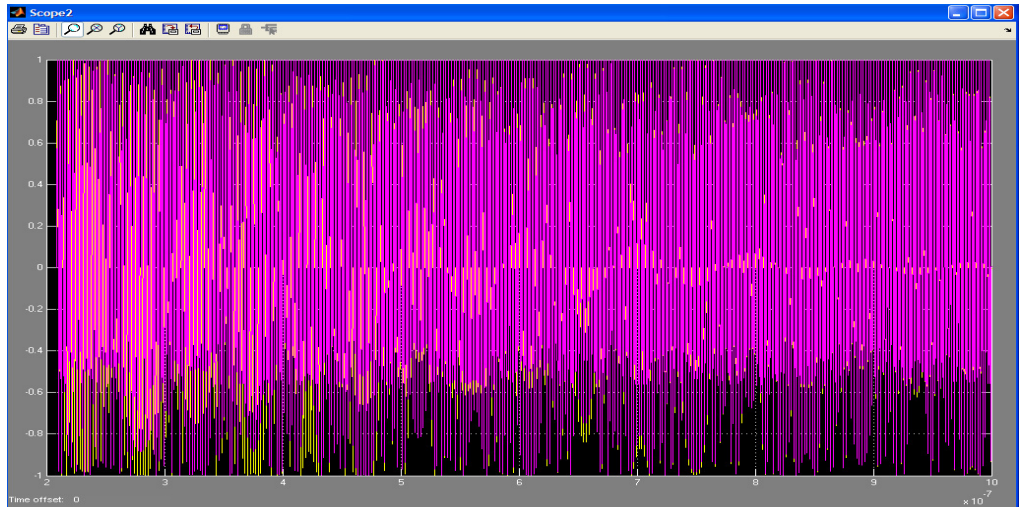

Figure 9. Charge pump PLL VCO output and input signal

Figure 7,8.9 shows Charge pump PLL filter output, Charge pump PLL Phase detector output and Charge pump PLL VCO output and input signal respectively these results is obtained by design and simulation of second order charge pump PLL, shows once the refernce signal is tracked then phase detector outputs with minimum phase differnce between input and output signal. 


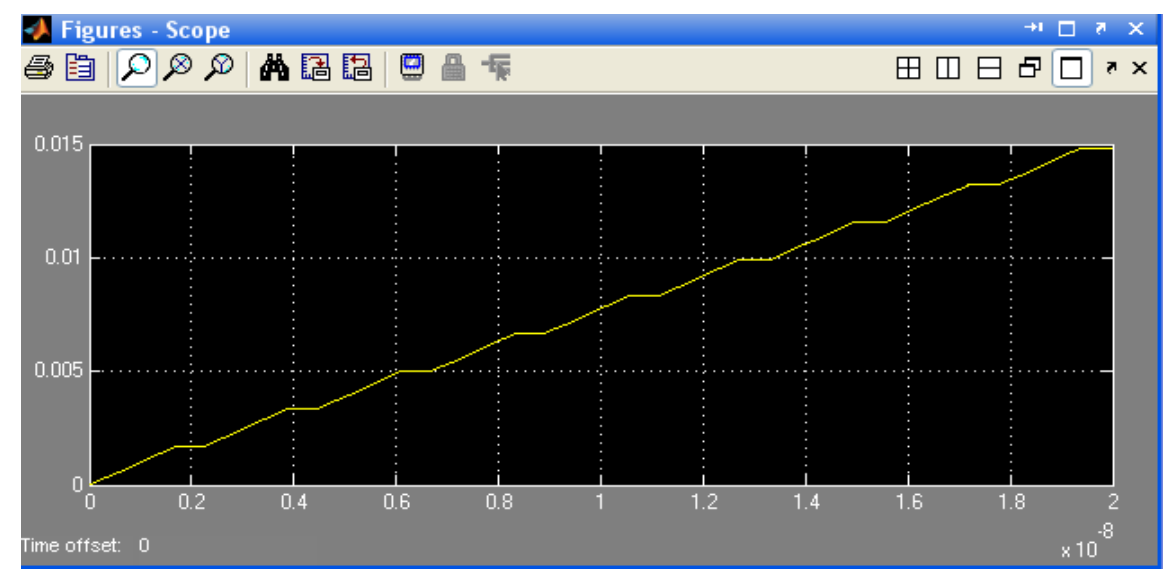

Figure 10. Third order Charge pump PLL filter output

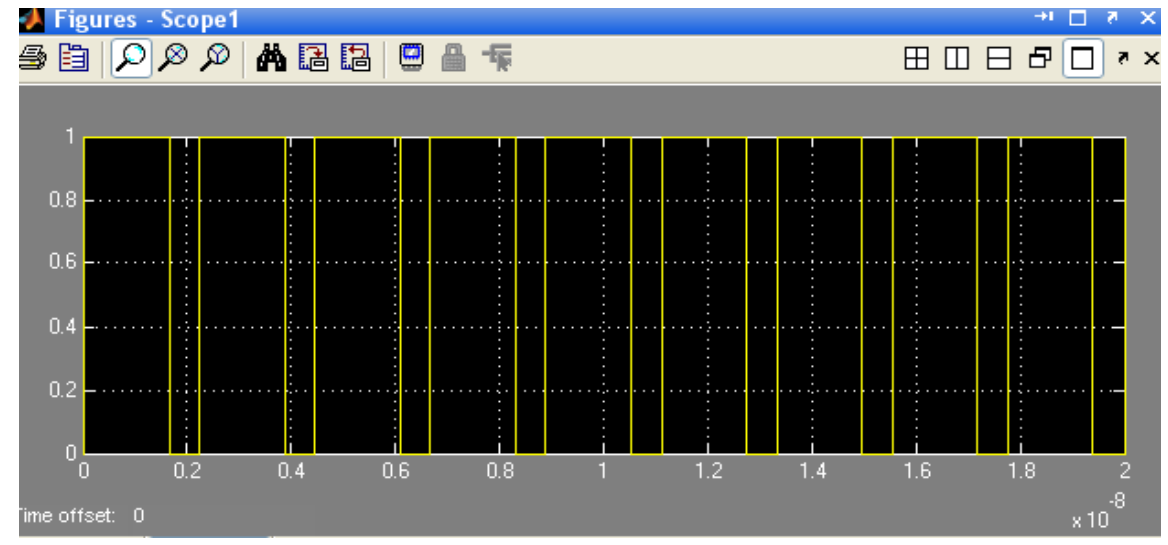

Figure 11. Third order Charge pump PLL Phase detector output

Figure 10, 11, 12 shows Third order Charge pump PLL filter output, Phase detector output and VCO output and input signalwith $\Delta \theta=90$ respectively. It can be obsered that when $\Delta \theta=90$, and the reference signal is track PD output is zero. Figure 13 shows the step response of third order system for different damping factor. It can be obsered that as the damping factor of the system increases the settling time decreases. 


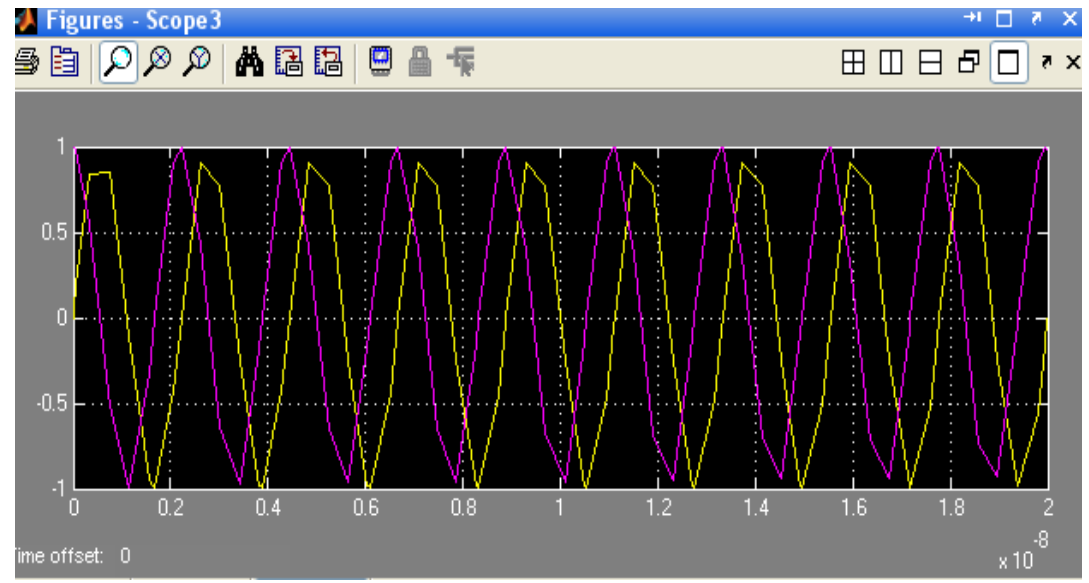

Figure 12. Third order Charge pump PLL VCO output and input signal

Analysis of third order PLL using Bode plot of open loop and closed loop transfer function are shown in figure 14,figure 15 respectively,from the open loop bode plot critical phase margin is obtained and stability of system obtained by closed loop bode plot. Previous work involved design of PLL for specific phase margin but this work gives design and analysis of PLL for critical phase margin and how its affect behavior of PLL in terms of its parameters by changing damping factor shown in table 2.

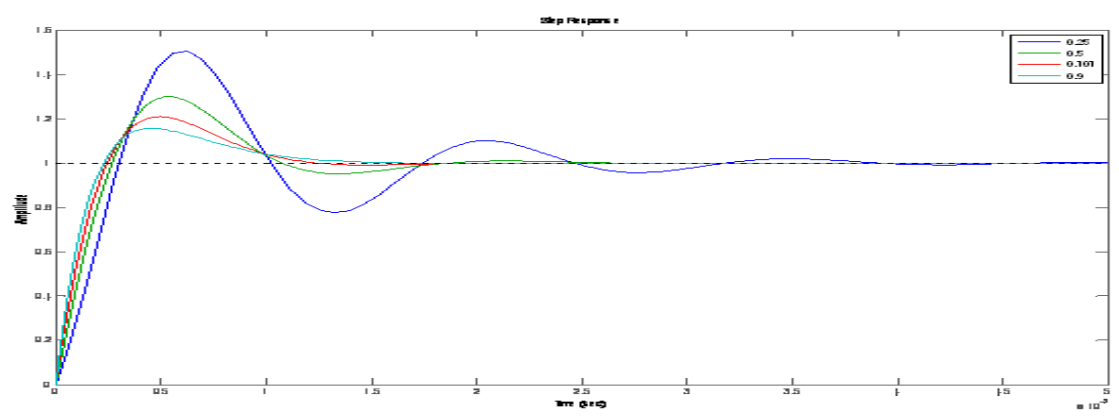

Figure 13. Step response for different values of $\underline{\xi}$ of Charge pump PLL 


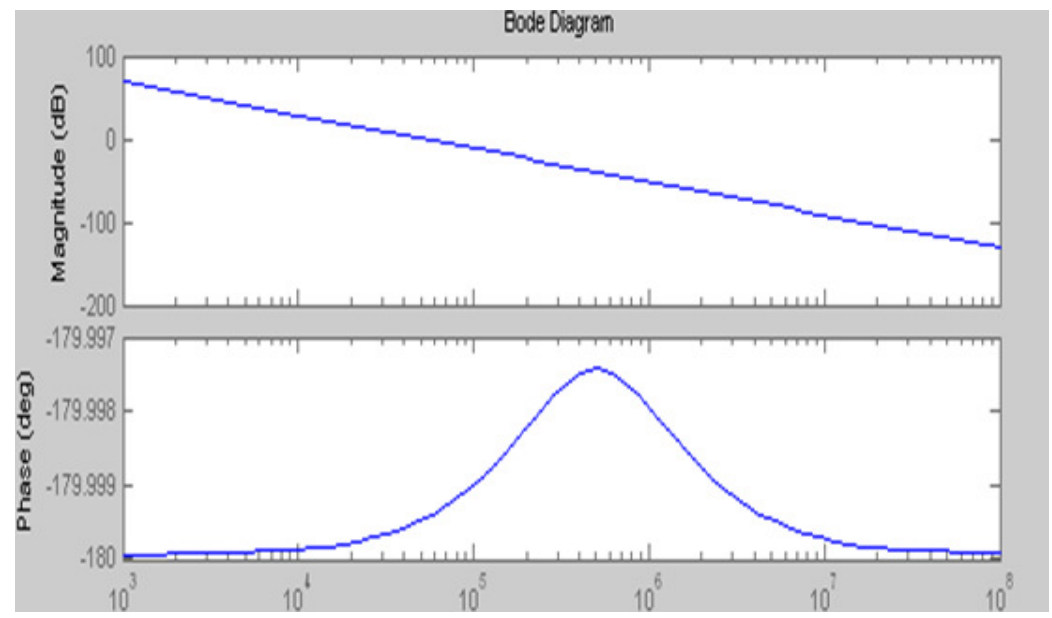

Figure 14. Open loop Bode plot of third order CPPLL

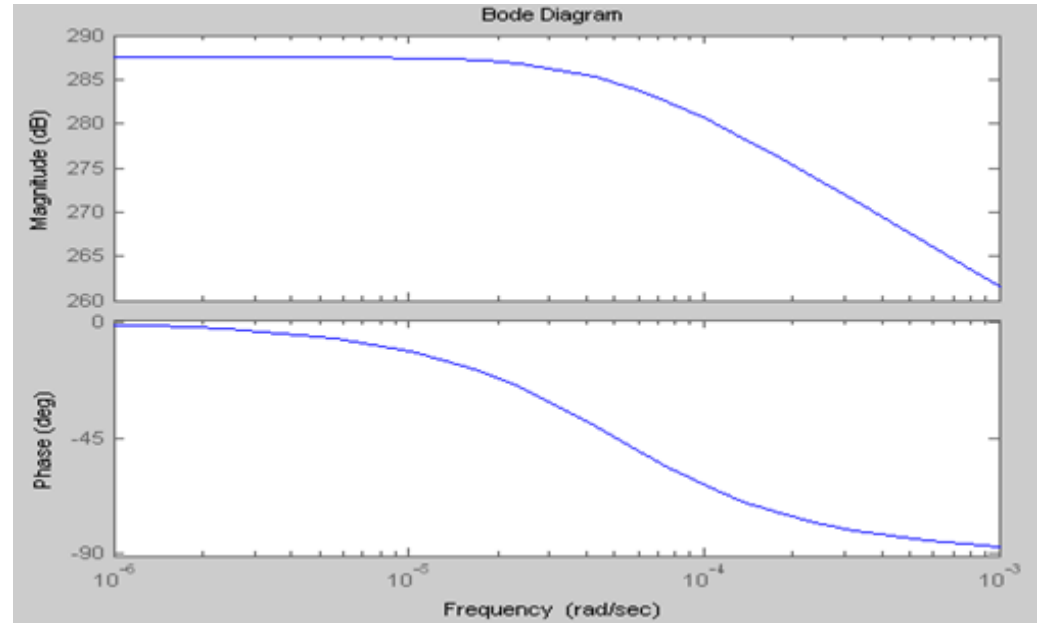

Figure 15. Closed loop Bode plot of third order CPPLL

\section{RESULT AND DISSCUSSION}

For the different type of PLL, the comparative study of obtained results of PLL for parameter such as setting time (sec to msec), Bandwidth(Hz to $\mathrm{MHz}$ ),Lock range(Hz-KHz) is shown in figure 16-24 


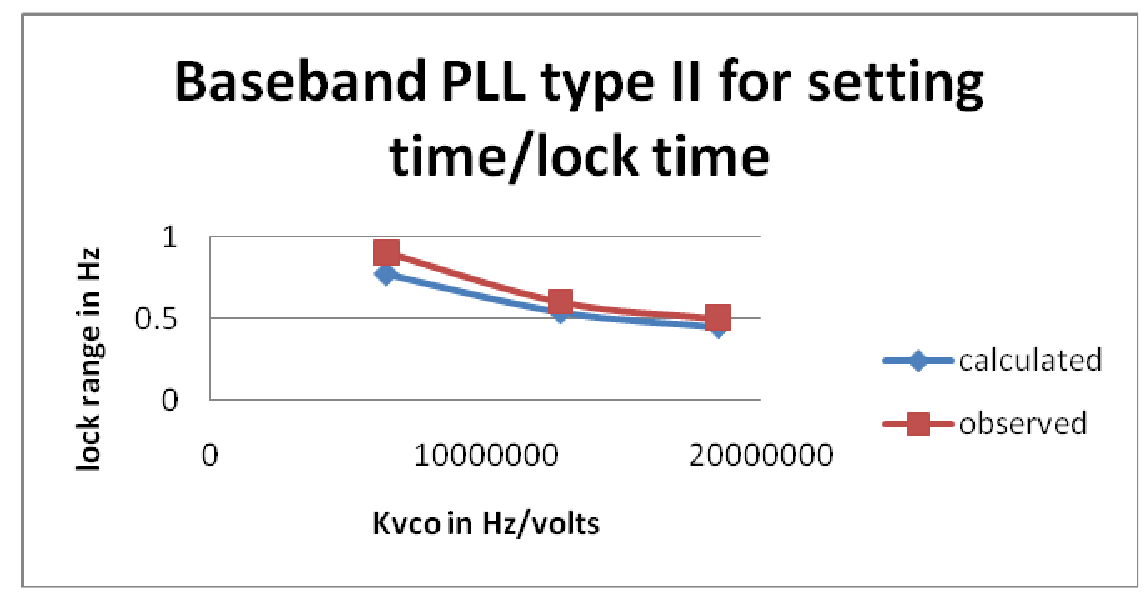

Figure 16. Baseband PLL TYPE II for lock time

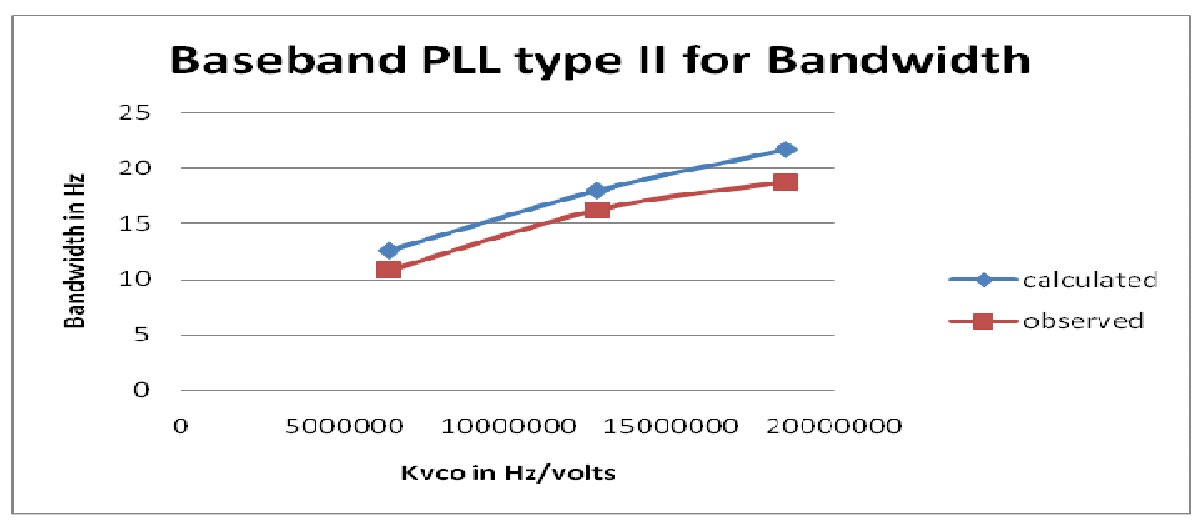

Figure 17. Baseband PLL TYPE II for Bandwidth

From figure 16,17,18, It can be found out that Baseband PLL can be used for narrow BW apllications such as GPS its around $(0-10 \mathrm{~Hz})$ since the drawback is as Kvco increases setting time increases therefore selection RC time constant is acritical issue. and its lock range is small in range of few $\mathrm{Hz}$. 


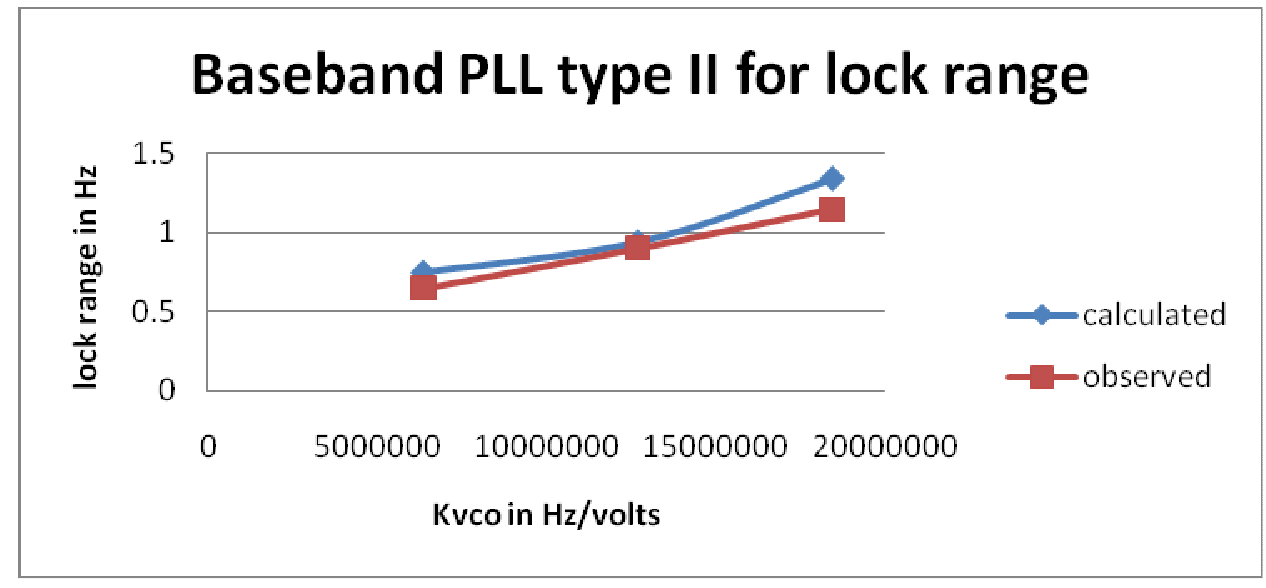

Figure 18. Baseband PLL TYPE II for lock range

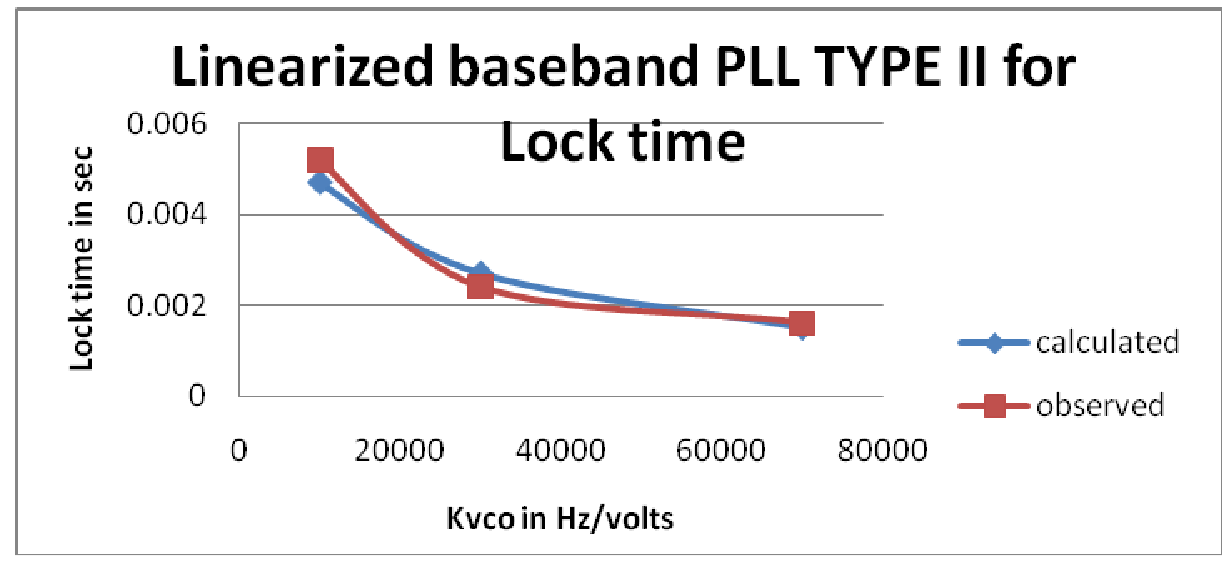

Figure 19.Linearized Baseband PLL TYPE II for lock time

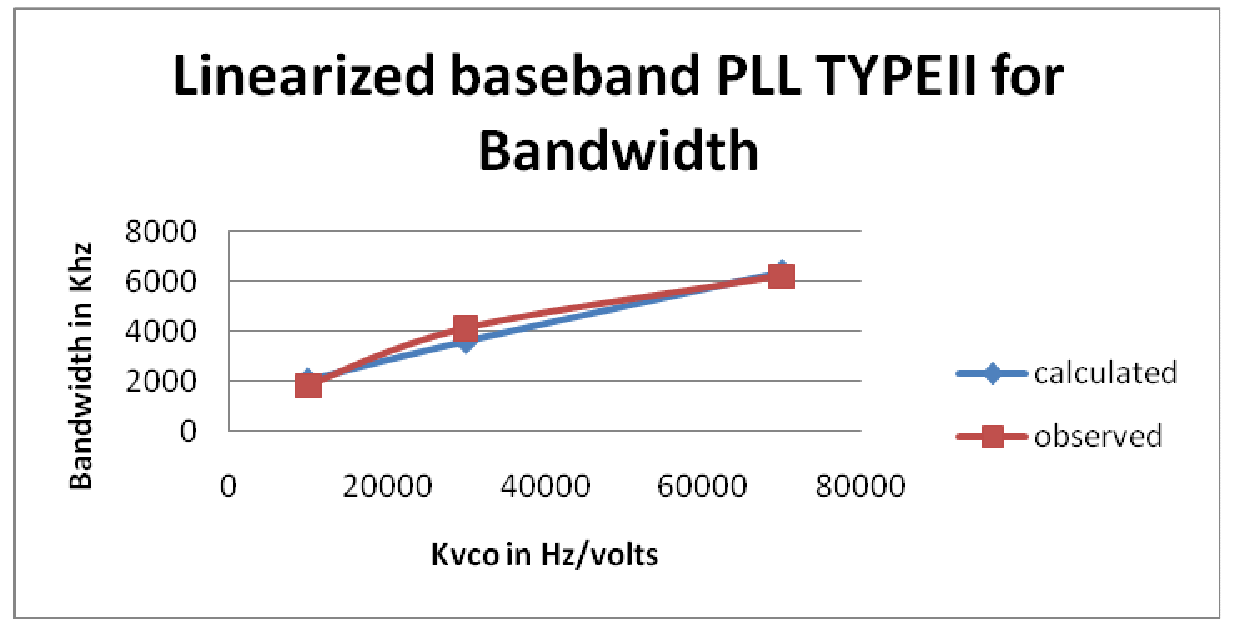

Figure 20.Linearized Baseband PLL TYPE II for Bandwidth 


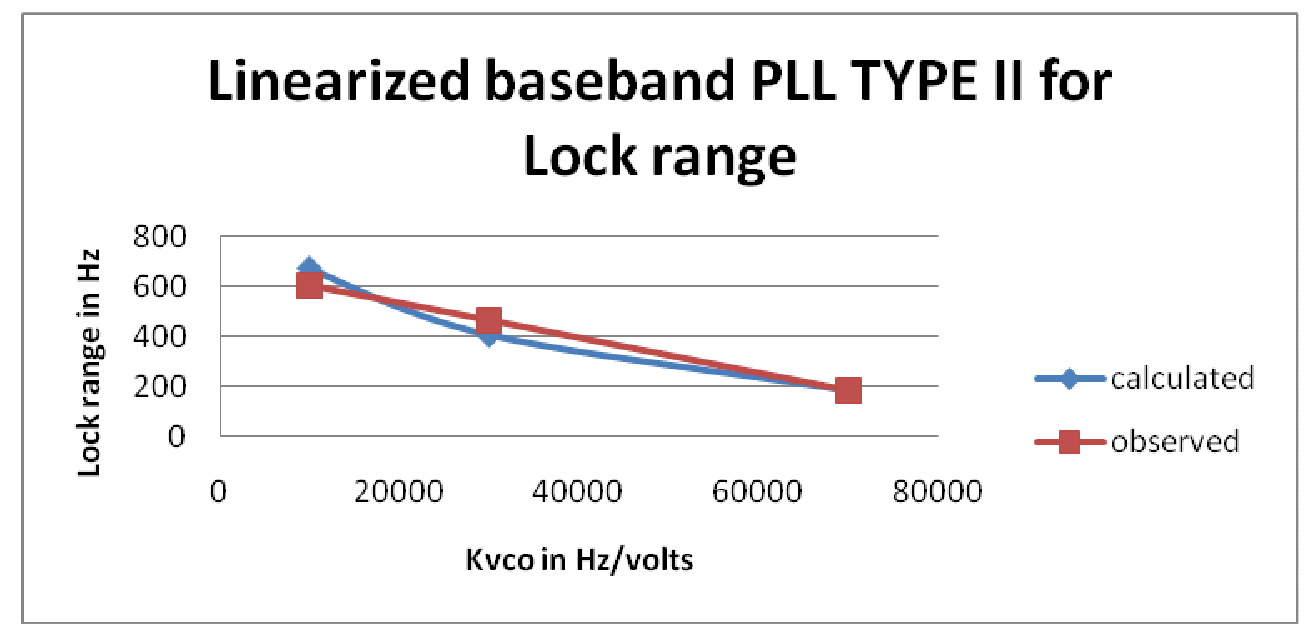

Figure 21.Linearized Baseband PLL TYPE II for lockrange

Figure 19,20,20 shows performance of linearized baseband PLL.and from the graph 21, It was found that,for Linearized PLL $\mathrm{K}_{\mathrm{VCO}}$ inreases its lock range decreases drastically. The linearized model and the nonlinearized model differ in that the linearized model uses the approximation $\sin (\Delta \theta(t)) \cong \Delta \theta(t)$ to simplify the computations. This approximation is close when $\Delta \theta(\mathrm{t})$ is near zero. Thus, instead of using the input signal and the VCO output signal directly, the linearized PLL model uses only their phases.

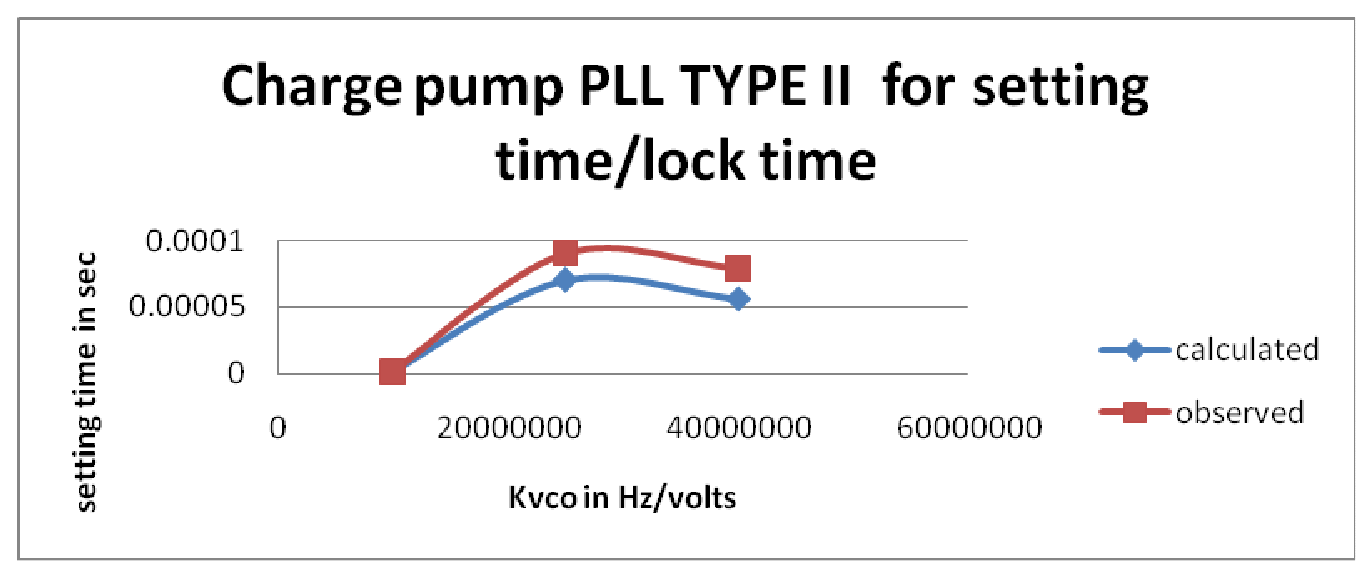

Figure 22.Charge pump PLL TYPE II for lock time

From table 2 it can seen that with this approach, we get faster settling time for critical phase margin. For this novel method of design and analysis of charge pump PLL considering parameters such as settling time, overshoot, capacitor ratio(m) and loop gain are obtained better 
results in terms of faster settling time, wide BW as compare to previous work where settling time in $\mu \mathrm{sec}$ and bandwidth in $\mathrm{KHz}$.

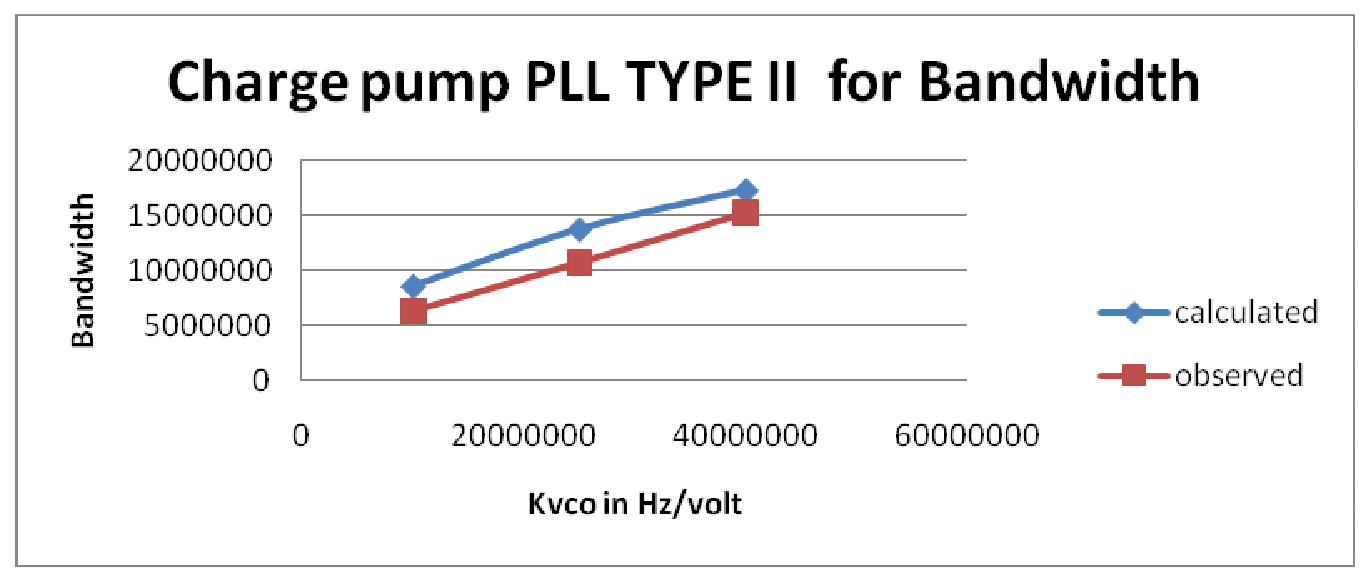

Figure 23.Charge pump PLL TYPE II for Bandwidth

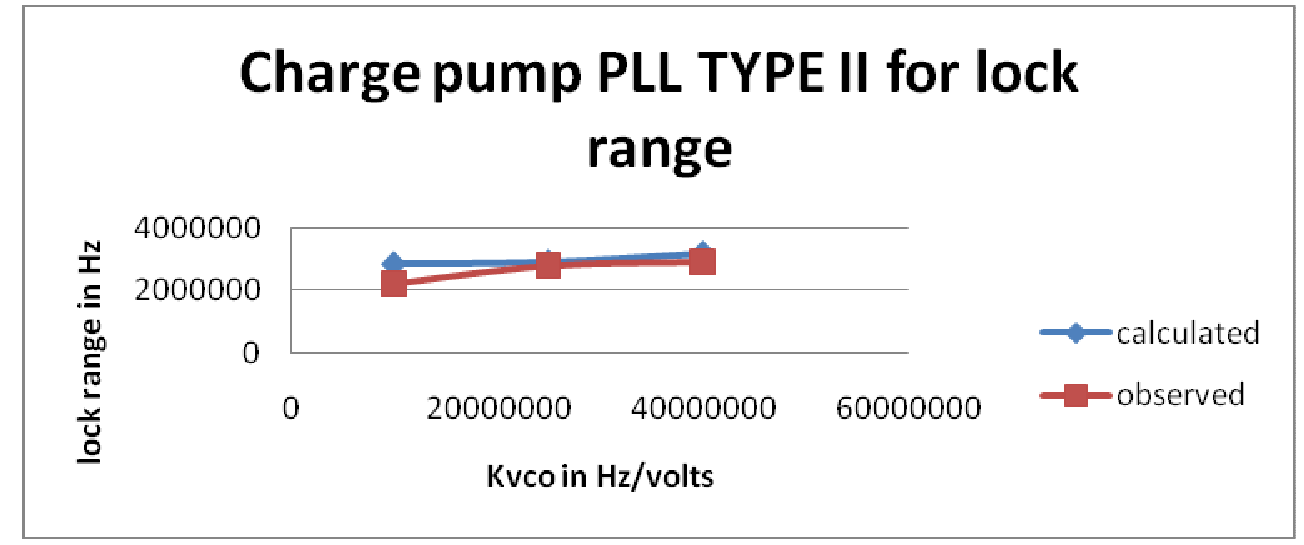

Figure 24.Charge pump PLL TYPE II for lock range

From the graph 22-24,It was observed that ,for Charge pump PLL we get wider Bandwidth [9],[11],[12],faster setting time and lage lock range [13].The comparative result table for baseband, Lineaized baseband and chgre pump PLL is listed in table 1. 
Table 1. Comparative result table for all types of PLL

\begin{tabular}{|c|c|c|c|c|c|c|c|}
\hline \multirow{2}{*}{$\begin{array}{l}\text { PLL } \\
\text { TYFE }\end{array}$} & \multirow{2}{*}{$\begin{array}{l}\text { KwCo itr } \\
\text { Hz'roits }\end{array}$} & \multicolumn{2}{|c|}{ Lock time } & \multicolumn{2}{|c|}{ LackRange } & \multicolumn{2}{|c|}{ Bandwidth } \\
\hline & & $\mathrm{Cal}$ & Obs & $\mathrm{Cal}$ & Obs & $\mathrm{Cal}$ & obs \\
\hline \multirow{6}{*}{$\begin{array}{l}\text { Baseba } \\
\text { nd PLL }\end{array}$} & 6.36 & $0.75 \mathrm{sec}$ & 0.9 & 0.75 & 0.65 & $12.5 \mathrm{~Hz}$ & $10.8 \mathrm{~Hz}$ \\
\hline & $\mathrm{KHz}$ wolts & & $s \theta$ & $\mathrm{Hz}$ & $\mathrm{Hz}$ & & \\
\hline & 127 & $0.54 \sec$ & 0.60 & 0.93 & $0.9394 \mathrm{~Hz}$ & $17.96 \mathrm{~Hz}$ & 16.24 \\
\hline & kHz'volts & & $\sec$ & $93 \mathrm{~Hz}$ & & & $\mathrm{~Hz}$ \\
\hline & $18.5 \mathrm{KH} /$ & $0.45 \mathrm{sec}$ & 0.52 & 1.33 & $1.145 \mathrm{~Hz}$ & $21.66 \mathrm{~Hz}$ & 18.74 \\
\hline & & & $\sec$ & $\mathrm{Hz}$ & & & $\mathrm{Hz}$ \\
\hline \multirow{6}{*}{$\begin{array}{l}\text { Charge } \\
\text { purnq } \\
\text { FLL }\end{array}$} & 100 & $1.13 \mu \mathrm{sec}$ & $1.5 \mu \mathrm{s}$ & 2.83 & 2.19 & $8.6 \mathrm{WHz}$ & 6.28 \\
\hline & Mho/volts & & $e c$ & $\mathrm{MHz}$ & $\mathrm{NHz}$ & & $\mathrm{MHz}$ \\
\hline & 250 & $70.4 \mu \mathrm{sec}$ & 90.5 & 2.89 & 2.78 & $138 \mathrm{MHz}$ & 152 \\
\hline & Mha'volts & & $\mu \mathrm{sec}$ & $\mathrm{MHz}$ & $\mathrm{WHz}$ & & $\mathrm{MHz}$ \\
\hline & 400 & $56.1 \mu \mathrm{sec}$ & 79.3 & 3.17 & 2.9 & $173 \mathrm{MHz}$ & $152 \mathrm{MHz}$ \\
\hline & Mhavolts & & $\mu \sec$ & $\mathrm{MHz}$ & $\mathrm{NHz}$ & & \\
\hline \multirow{3}{*}{$\begin{array}{l}\text { Litieati } \\
\text { zed } \\
\text { baseba } \\
\text { nd PLL }\end{array}$} & $\begin{array}{c}10 \\
\text { Khorrolts }\end{array}$ & 4.7 msec & $\begin{array}{l}5.2 \\
\text { misec: }\end{array}$ & $\begin{array}{l}671 . \\
2 \mathrm{~Hz}\end{array}$ & $601.98 \mathrm{~Hz}$ & $\begin{array}{c}2.0307 \\
\mathrm{KHz}\end{array}$ & $\begin{array}{c}1.8293 \\
\mathrm{KHz}\end{array}$ \\
\hline & $\begin{array}{c}30 \\
\text { Khawolts }\end{array}$ & 27 msec & $\begin{array}{c}2.4 \\
\text { mose: }\end{array}$ & $\begin{array}{l}405 . \\
2 \mathrm{~Hz}\end{array}$ & $464.97 \mathrm{~Hz}$ & $\begin{array}{c}3.5922 \\
\mathrm{KHz}\end{array}$ & $\begin{array}{l}4.119 \\
\mathrm{KHz}\end{array}$ \\
\hline & $\begin{array}{c}70 \\
\text { Khz'rolts }\end{array}$ & 1.5 msec & $\begin{array}{l}1.6 \\
\text { minec: }\end{array}$ & $\begin{array}{l}186 . \\
0 \mathrm{~Hz}\end{array}$ & $\begin{array}{c}182.0765 \\
\mathrm{~Hz}\end{array}$ & $\begin{array}{c}6.3493 \\
\mathrm{KHz}\end{array}$ & $\begin{array}{l}6.213 \\
\mathrm{KHz}\end{array}$ \\
\hline
\end{tabular}

Table 2.Simulation results for 0.707 and 0.9

\begin{tabular}{|l|l|l|}
\hline Parameter & $\xi=0.707$ & $\xi=0.9$ \\
\hline Settling time & $125.7 \mathrm{nsec}$ & $98.76 \mathrm{nsec}$ \\
\hline Overshoot $\%$ & $1.18 \%$ & $0.0000347 \%$ \\
\hline $\mathrm{m}$ & 0.000083 & 0.00001 \\
\hline Loop gain & $4.575 \mathrm{Mhz}$ & $7.9056 \mathrm{Ghz}$ \\
\hline
\end{tabular}

\section{CONCULSION}

Design and Analysis of PLL parameters using Mathematical model and the behavior model of PLL is tested with MATLAB simulink tool. The effect on parameters of second order and third 
order PLL at $450 \mathrm{Mhz}$ is discussed in this work. Simulation results show that $\xi$ and $\omega_{n}$ affect the behavior of different PLL types. From the observed results, it is found out that , Linearzed PLL is not used widely in communication applications due to constraint of smaller lock range for higher value of $\mathrm{K}_{\mathrm{Vco}}$. The use Baseband PLL is restricted to for narrow BW applications such as GPS systems in mobile communication whereas, Charge pump PLL can be widely used for many communication application due to its advantage as it provides wider Bandwidth, less setting \& wider lock range.

Design and simulation of third order PLL by propose novel method is more efficient to provide stability of system using Matlab/ Simulink model and this novel method shows very good precision in designed parameters for wider communication applications.

\section{REFERENCES}

[1] A. B. Grebene, The monolithic phase-locked loop - a versatile building block, IEEE Spectrum, vol. 8, pp.38-49, March 1971.

[2] B. Razavi (ed.), Monolithic Phase-Locked Loops and Clock Recovery Circuits, IEEE 2003.

[3] Gursharan Reehal, A Digital Frequency Synthesizer Using Phase Locked Loop Technique” 1998

[4] F. M. Gardner, Charge-Pump Phase-Lock Loops, IEEE Trans. On Communications, vol. 28, pp. 1849-1858, November 1980.

[5] F.M Gardner, Phase lock Techniques, 2nd ed., John-Wiley \& Sons, Inc., NY, 1979.

[6] K. H. Cheng, W. B. Yang, and C. M. Ying,A dual-slope phase frequency detector and charge pump architecture to achieve fast locking of phase-locked loop, IEEE Trans. Circuit and System II, vol. 50, pp. 892-896, Nov. 2003.

[7] Liu yu-zhen, Design of phase-Locked loop based on SIMULINK, Liaoning Technical University's Transaction, vol. 23, no. 2, pp. 236-237, 2004.

[8] L. C. Liu and B. H. Li,Fast locking scheme for PLL frequency synthesiser Electronics Letters, vol. 40, pp. 918-920, July 2004

[9] P.E. Allen ,PLL Design Equations \& PLL Measurement" ECE 6440 - Frequency Synthesizers

[10] R. E. Best, Phase-Locked Loops: Theory, Design and Applications. New York McGraw-Hill, 1984

[11] R.E. Best, Phase-Locked Loops: Design, Simulation, and Applications, 4th edition, McGraw-Hill, 1999 (4th edition)

[12] ]T. A. Telba and Abdulhameed Al-MazrooA, Wideband Low Jitter Frequency Synthesizer Modeling and Simulation, IJCSNS International Journal of Computer Science and Network Security, VOL.10 No.1, January 2010

[13] Ms. Ujwala A. Belorkar and Dr. S.A.Ladhake, Dssign of loe power phase Locked Loop (PLL) using $45 N M$ VLSI TECHNOLOGY, International journal of VLSI design \& Communication Systems ( LSICS ), Vol.1, No.2, June 2010

[14] F. You, and S. He, “Analysis of Third-order Charge Pump PLLs,"IEEE conf., 2004, pp. 1372-1376

[15] A.Carlosena, A.M. Lazaro, "A Novel Design Method for Phased-Locked Loops of any Order and Type,” IEEE conf., 2006, pp. 569-573. 
International Journal of VLSI design \& Communication Systems (VLSICS) Vol.2, No.1, March 2011

[16] Yunfei Ye ,Ming Zhang "Analysis and Simulation Three Order Charge Pump Phase Locked Loop" 978-1-4244-2108-4/08/\$25.00 @ 2008 IEEE

[17] G.-C. Hsieh and J. C. Hung, "Phase-locked loop techniques-A survey,"IEEE Trans. Ind. Electron., vol. 43, no. 6, pp. 609-615, Dec. 1996.

[18] J. X. Shen and S. Iwasaki, "Sensorless control of ultrahigh-speed PMbrushless motor using PLL and third harmonic back EMF," IEEE Trans.Ind. Electron., vol. 53, no. 2, pp. 421-428, Apr. 2006.

[19] M. A. Pérez, J. R. Espinoza, M. Torres, and E. A. Araya, "A robust PLL algorithmto synchronize static power converters with polluted AC systems,"in Proc. 32nd Annu. Conf. IEEE IECON, Nov. 2006, pp. 2821-2826. 